vomiting, and creatin and creatinin did increase without the typical vomiting. In many cases when we had recurrent vomiting, I did not get much increase in creatin and creatinin before vomiting. Of course acidosis and acid bodies come up at the same time-I believe in many cases owing to the withdrawal of carbohydrates.

Dr. Joseph I. Linde, New Haven, Conn.: It is important to get complete specimens of urine, or at least several specimens during the day. Pus is not present in all specimens during the day, and if several specimens are not examined one may easily fail on the diagnosis.

Dr. Henry F. Helm holz, Chicago: I wish to emphasize a point made by $\mathrm{Dr}$. Linde, not only to take several specimens on one day, but specimens for several days ruming, especially in those chronic cases, in which one may find no pus for scveral days. In recurring cases, in which the symptoms are indefinite, one sometimes gets a sudden gush of pus after practically negative urinary examinations covering a period of several days. With regard to the finding of albumin in the urine in older children, one case is well recognized, namely, orthostatic albuminuria, which should be considered, because, by means of exercises, this condition can be cured. Whether or not it is of any great harm to the clinild to be excreting albumin, is not for me to decide. In this well-defined group of orthostatic albuminuria we have an explanation of why the child is passing albumin. Dr. Freeman called attention to overfeeding; it seems to me just as important to recognize cases of acidoses caused by underfeeding. As Dr. Sedgwick has said, the withdrawal of carbohydrates gives rise to this condition, and in children who are underfed a very good indication of this is the presence of diacetic acid in the urine.

Dr. W. W. Butterworth, New Orleans: If, through Dr. Freeman's paper the attention of the general practitioner can be called to the great need of examining the urine of infauts and children more frequently than is generally done, we will have accomplished a great deal. It is easy to secure a specimen of urine from infants-especially female infants. Apart from albumin and sugar examination, the test for indican, acetone bodies and the presence of pus is important. Another thing which should be mentioned is the frequency of pyelitis occurring in boys as well as in girls. At the last meeting of the International Medical Association, Dr. Thompson of Edinburgh reported twenty-seven cases of pyelitis occurring in boys. I, as well as others, had lost sight of the fact that it occurs more frequently in girls than boys. My fatalities have occurred in boys instead of girls. Just why is not clear to me. I believe we are apt to overestimate the importance of acetone and diacetic bodies in the urine. Almost any febrile disturbance will cause their presence. The simple finding of them does not mean acidosis.

Dr. Henry Heiman, New York: First in importance is the examination of the urine at various times. In orthostatic albuminuria, if we examine the first specimen before the patient is out of bed, we will find it negative. As soon as lie is up and around the albuminuria will be present. We know this is probably due to pressure on the venous systciil of the kidneys. It is better to take morning and evening specimens in cases of suspected orthostatic albuminuria. In infectious diseases, when we examine the first twenty-fourhour specimen we find it as a rule containing albumin, but we all know that real nephritis occurs later, as in the third wcek in scarlet fever. With regard to obtaining urine in children, I have been fairly successful with Dr. Chapin's receptacle. In females I never hesitate to catheterize when necessary with a small ureteral catheter. This is thoroughly sterilized, of course. There is no difficulty in obtaining urine. With regard to types of pyelitis, we all believe we have ascending, descending and transparietal types. My experience has been that they are much more frequent, in New York, in females than in males. We should state specifically with what type of pyelitis we are dealing. The majority are due to the Bacillus coli communis. I have one case in the hospital of the pyocyaneus type. I believe the majority are of the ascending type. The colon bacillus has been found in the blood, but in rare instances. With regard to the treatment of these patients, I must say if they do not get well in ten or twelve days with or without urotropin, they become chronic. The Germans belicve, in such cases as have been mentioned, in which there is free urine for several days and a relapse, that it is due to punctate abscesses in the cortex of the kidney. For the diagnosis of these cases Dr. Edwin Beer has given an excellent test-methylene blue. For a few days the urine will be green, then it becomes normal, then when an abscess bursts, it will be green again. This test is a very useful one.

Dr. Kate C. Meade, Middletown, Conn,: Is it possible, by regulating the urine, to control the eczema which these children sometimes have?

Dr. R. G. Freeman, New York: A variation in the amount of pus in the urine at different times in the day does of course occur. As to using the urine from a squeezed diaper, that is better than nothing, but one never knows what the diaper may contain, and what it does contain will appear in the urine. It is perfectly simple to obtain a specimen in a clean vessel in all cascs. I think modifying the urine aids much, but diet is the main factor in eczema.

\section{AMEBIC DYSENTERY IN CHILDREN *}

L. R. DeBUYS, M.D.

Assistant Professor Diseases of Children, Tulane University of Louisiana

NEW OREEANS

Amebic dysentery is a relatively rare disease in children, not because children are not susceptible to the infection but because they are less exposed to the etiologic factors which cause the infection in the adult. It is possible that in children it may exist much more often than is believed but may escape detection. The four cases reported below are instances of this.

In the Charity Hospital in New Orleans where there have been seen in the out-patient department for the last eight and a half years an average of 20,543 new cases annually, and where there have been admitted annually an average of 11,077 cases, or where 94,161 cases have been admitted, only 313 were cases of amebic dysentery, and of these four occurred in children under 12 years. Two of these were in my service.

At the Touro Infirmary in my service in over 3,000 children there were four cases of amebic dysentery. Two of these children were admitted to the Charity Hospital, because the Touro beds were filled, and are included in the four cases in the Charity Hospital. Besides my four cases at the Touro Infirmary there were two others, making a total of six cases at this institution.

Of the eight cases, one, after the condition was diagnosed, deserted.

Amebic dysentery is more prevalent in the male than in the female, due, it is generally believed, to the more active life of the male with the incident greater exposure; and so it might be argued, the lesser exposure may hold good for the relative infrequency in children. The younger the child the less often is the disease found. This is in accord with our belief of the sources of infection, more particularly water and green vegetables, as the smaller babies have boiled water, as a rule, and do not yet have vegetables. As they grow older the exposure, and consequent liability to infection is greater.

The symptoms of amebic dysentery in children do not differ from those in the aduit. The abdominal

* Read before the Section on Diseases of Children at the Sixty-Fifth Annual Session of the American Medical Association, Atlantic City, N. J., June, 1914. 
pain, the frequent stools containing mucus, blood and, at times pus, the tenesmus, anorexia, indigestion, anemia, emaciation and low temperature, loss of weight, flabbiness of muscles, dry skin and sallow complexion are more or less constantly found, depending on the severity of the disease. The blood picture is one of secondary anemia.

The diagnosis is not difficult to make if a microscopic examination of the warm. liquid stool, free from urine, is made; or better still, if a rectal tube is passed and the bloody mucus or small pieces of necrotic tissue thereon are examined on warm slides. The ameba will be most readily found in this way. The condition from which amebic dysentery is to be differentiated in children is bacillary dysentery. In the latter condition the onset is usually more acute, temperature higher, systemic disturbance greater, the child is more toxic and less sallow, and the agglutination test may be positive, and the dysentery bacilli but no amebas are found in the stools. The facies in the two dysenteries are different and characteristic in each. daily, and as long as amebas were found to give 1 grain emetin hypodermatically at one dose daily. When the amebas were no longer found the tube was passed every other day for two or three observations; then the interval of passing the tube was lengthened. The passing of the tube was not discontinued until after magnesium sulphate or castor oil was given and no amebas found.

The diet should be liquid until the blood and mucus disappear, when soft food may be given. Rest is absolutely essential, not only to the individual, but to the bowel. Emetin seems to provide rest to the latter.

\section{CASE REPORTS}

CASE 1.-F. A., white male, 1 year and 11 months old, native of Louisiana and resident of Donner, La., was brought to my clinic at Touro Infirmary, Nov. 8, 1912, because of loose, bloody stools.

His family history was negative, except that there had been two miscarriages. There were three well children and no bowel trouble in the family. He was a full term child and born after a difficult labor. He was breast-fed

TABIE 1.-DATA IN CASE 2*

\begin{tabular}{|c|c|c|c|c|c|c|c|c|c|c|c|c|c|c|c|c|c|}
\hline \multirow{2}{*}{$\begin{array}{l}\text { Dat } \\
1913\end{array}$} & \multirow{2}{*}{$\begin{array}{c}\text { Temp. } \\
\text { Min. } \\
\text { and } \\
\text { Max. }\end{array}$} & \multirow[b]{2}{*}{ Med. } & \multirow{2}{*}{$\begin{array}{l}\text { Tube } \\
\text { Passed }\end{array}$} & \multirow[b]{2}{*}{ Ameba } & \multicolumn{2}{|c|}{ Stools } & \multirow[b]{2}{*}{ Description } & \multirow[b]{2}{*}{ Remarks } & \multirow[b]{2}{*}{ Diet } & \multicolumn{8}{|c|}{ Blood } \\
\hline & & & & & Day & Night & & & & $\underset{\%}{\mathrm{Hb}}$ & R.13.C. & W.B.C. & Neut. & S.L. & $\underset{\%}{\text { L.M. }}$ & $\begin{array}{c}\text { Eos. } \\
\%\end{array}$ & $\underset{\%}{\mathrm{Bas}}$ \\
\hline $7 / 25$ & $98.6-100$ & & & & & 0 & & & & 50 & $4,116,000$ & 14,600 & 67 & 23 & 4 & 6 & \\
\hline $7 / 26$ & $90.6-100$ & $\begin{array}{l}\text { Emetin } \\
\text { \&/s gr. }\end{array}$ & + & + & 3 & 3 & $\begin{array}{l}\text { Loose; brown; } \\
\text { blood; mucus }\end{array}$ & $\begin{array}{l}\text { Complained of } \\
\text { pain in abdomen }\end{array}$ & Liquid & & & & & & & & \\
\hline $7 / 27$ & $99.4-100$ & Emetin & + & + & 3 & 1 & $\begin{array}{l}\text { Loose; brown; } \\
\text { blood; mucus }\end{array}$ & Pain & & & & & & & & & \\
\hline $7 / 28$ & $98 \quad-100$ & Emetin & + & + & 0 & 0 & ............................ & $\begin{array}{c}\text { Feeling comfort } \\
\text { able }\end{array}$ & & & & 14,000 & 61 & 24 & 8 & 6 & 1 \\
\hline $7 / 29$ & $98-99.4$ & Emetin & + & $+t$ & 0 & 0 & $\ldots \ldots \ldots \ldots \ldots \ldots \ldots$ & Conifortable & & & & & & & & & \\
\hline $7 / 30$ & $99-100$ & $\begin{array}{c}\text { Mag. Sulph. } \\
2 \mathrm{dr} .\end{array}$ & + & - & 3 & 0 & $\begin{array}{l}\text { Liquid and yel- } \\
\text { low; no blood; } \\
\text { no mueus }\end{array}$ & .. & Liquid & & & $.11,000$ & 69 & 22 & 8 & 1 & \\
\hline $7 / 31$ & $99.2 \cdot 99$ & $\ldots \ldots \ldots \ldots$ & + & - & 1 & 0 & $\begin{array}{l}\text { Semisolid; yel- } \\
\text { low; no blood; } \\
\text { no mucus }\end{array}$ & $\begin{array}{l}\text { Tube passed } 22 \\
\text { hrs. after Mag. } \\
\text { Sulph. }\end{array}$ & Soft & & & & & & & & \\
\hline $8 / 1$ & $98-99.8$ & & & 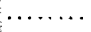 & 0 & 0 & ………, & 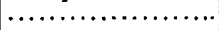 & Soft & & & & & & & & \\
\hline $8 / 2$ & 99.8 & $\begin{array}{l}\text { Milk Mag. } \\
\text { Mag. Citr. }\end{array}$ & + & - & 0 & 0 & 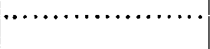 & $\ldots \ldots+\cdots \cdots \cdots+\cdots, \cdots$ & Sult & & & & & & & & \\
\hline $\begin{array}{l}8 / 3 \\
8 / 4\end{array}$ & $\begin{array}{l}99.8 \\
99.8\end{array}$ & Mä........... & + & $\cdots$ & $\begin{array}{l}0 \\
1\end{array}$ & $\begin{array}{l}0 \\
0\end{array}$ & Liquid.... & & & & & 9,300 & 57 & 25 & 8 & & \\
\hline $8 / 5$ & 99.8 & $\begin{array}{c}1 \leq 2 \text { oz. } \\
\text { Milk Mag. }\end{array}$ & + & - & 1 & 0 & Semisolid... & & Full diet & & & & & & & & \\
\hline $8 / 6$ & 99.8 & & & & & & & $\begin{array}{l}\text { Hungry between } \\
\text { me..Is }\end{array}$ & & & & & & & & & \\
\hline
\end{tabular}

* Urine negative except for indican.

f Inactive.

The prognosis depends on the severity of the disease and the complications, more particularly abscess of the liver, terminal infection, exhaustion in protracted cases, and intercurrent diseases.

Conclusions cannot be drawn from a few cases but in a condition as infrequent as is amebic dysentery in children, it is excusable to venture some suggestions from the study of a few cases.

The treatment of the seven cases (because one of the eight patients deserted after the diagnosis was made) referred to in the beginning of this paper consisted of ipecac in two cases and emetin in five cases. The two patients who were given the ipecac in the form of pills were 11 years and 6 years and they received 380 grains in 27 days and 243 grains in 25 days, respectively. In a third case ipecac was attempted but because of the inability of the patient to swallow the ipecac pills emetin was given with, I am told, satisfactory results. The four remaining patients, aged 8\%/12, 7, 4 and 4 years, respectively were given emetin. The 7 -year-old child was given $42 / 3$ grains in five days, being given $1 / 3$ grain three times a day. The amebas disappeared from the stools on the fourth day. The plan adopted in the treatment of my three patients was to pass the tube and after his fourteenth month ate everything. His development was nornal. He had had no other illnesses.

In June, 1912, his present trouble began with frequent stools, twelve to fifteen a day, containing slime and much blood, and accompanied with pain and straining. In August there appeared a lump in the left inguinal region which disappeared from time to time. During the present illness the patient has had slight fever.

Physical examination showed a fairly developed child weighing 21 pounds. He had a small left inguinal hernia. A rectal tube was passed and amebas were found. Otherwise his examination was negative. $\mathrm{He}$ was given an admission card but was not seen again. This is the patient that has been alluded to as having deserted.

CASE 2.-W. O., white male, 4 years old, native of Louisiana, was brought to me July 25,1913 , from Baton Rouge, La., with a complaint of frequent and bloody stools.

His father and mother were both living and healthy as were also his two sisters and one brother. There was no other member in the household with bowel trouble.

He was a full-term child delivered normally. He was fed exclusively on the breast for nine months, after which cereals and a proprietary food were given until his eleventh month when he was gradually put on a full diet, eating everything at the age of three. When 2 years old he had fever for four days which was called "malaria." The diagnosis, however, was not confirmed microscopically. 
The patient lived in the suburbs of the city but used the water furnished by the city's waterworks. He was very fond of green vegetables, which he frequently stole and ate.

In November, 1912, he ate a great number of green pecans and within a week afterward his stools became loose, there being two or three movements daily. About one month later his stools became worse and the movements were accompanied by severe straining. They contained a great deal of blood and mucus. His stools were very frequent-from needle, was kept in bed and was put on liquid diet. In the next twenty-four hours he had six stools which were loose, dark brown and contained mucus and blood. He complained of pain in his abdomen and strained much at stool. The next day the tube was passed again, amebas found, and emetin, 1 grain by needle was given. He continued to complain of pain in the abdomen, but straining at stool was not so marked. During the next twenty-four hours he had only four stools which were of the same character as during

TABLE 2.-DATA IN CASE 3 *

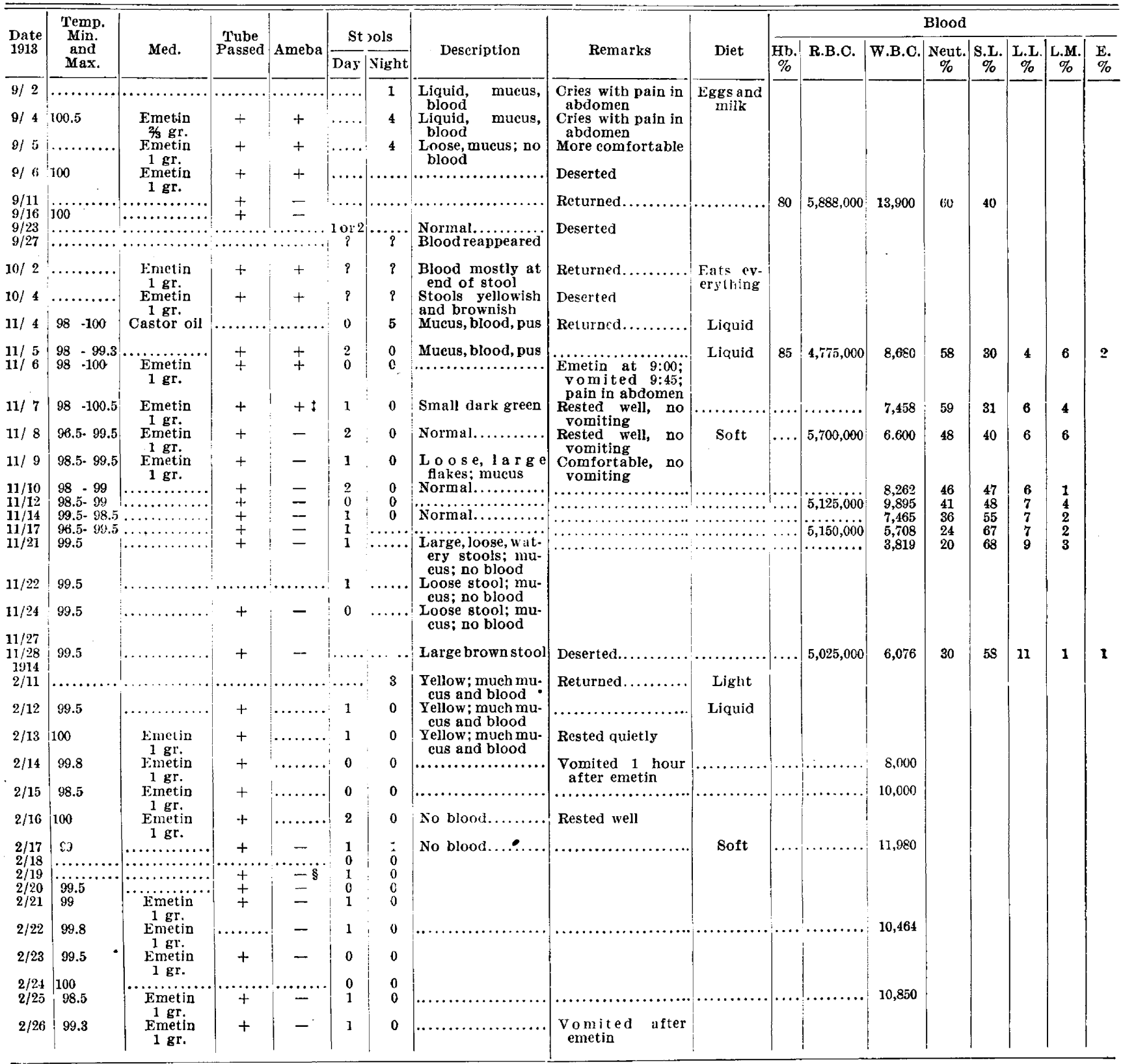

* Urine negative except for indican

Few encysted; non-active.

$\$$ Red blood-corpuscles.

twelve to twenty-six daily. He was relieved somewhat after a consultation was held by two physicians, but this relief was only temporary. He had experienced periods of relief followed by relapses intermirtently since the onset of the disease. The patient had lost much weight from December, 1912, to March, 1913.

He was admitted into Touro Infirmary on the evening of Juiy 25, 1913, with a temperature of $98.6 \mathrm{~F}$., pulse 102, respiration 24 . He had no stool during the night.

On the morning of July 26 a rectal tube was passed and amebas were found. He was given emetin, $2 / 3$ grain, by the previous twenty-four hours. His urine examination was negative, except that it contained much indican.

On July 28 the tube was passed, amebas found, though not so many, and another hypodermic of emetin, 1 grain, was given. There were no stools in the twenty-four hours following and the patient was fairly comfortable.

On July 29 the tube was passed and a few amebas (inactive) were found. Emetin, 1 grain, by needle was again administered. As before there were no stools in the twenty-four hours, but the patient remained in a perfectly comfortable condition. 
On the morning of July 30 the passing of the tuhe showed no amebas. No emetin was administered but magnesium sulphate $3_{\text {ii }}$ was given, from the effect of which he had three stools which were liquid and yellow and contained no blood and no mucus.

The tube was passed on the morning of July 31, twentytwo hours after the magnesium sulphate was given and no amebas were fotnd. He was allowed to have soft food and continued to improve in every way. There was a tendency toward constipation which was met by the administration of milk of magnesia. The tube was passed every other day until Aug. 4, 1913, with negative findings. On August 4 lie was again given magnesium sulphate and again the passing of the tube twenty-four hours afterward was negative. He was then placed on full diet and was hungry between meals. On August 8, after a negative finding on passing the tule, he was discharged as cured. The patient weighed 32 pounds, 11 ounces on July 27, 1913, and 34 pouncts, 2 ounces on Aug. 4, 1913. Wassermann made on admissiotn, July 26, 1913, was negative.

On August 24 he was brought back for observation. His parents stated that the previous week he had had as many was discontinued. His development was normal. At 18 months he had measles and whooping-cough, when he was ill for about four or five weeks.

He had used orly city water but ate a considerable amount of candy from different stores, and he also ate some green fruit.

The present illness began fifteen weeks previous to this report, when patient complained of pain in his stomach and passed blood and mucus in his stools. He was taken to one of the hospitals where he was treated for two weeks without any results. Some time afterward he was taken to a physician who gave him a white medicine (presumably bismuth) which had a transient beneficial effect. In a week, however, the condition reappeared and the patient was brought to me. During the attacks of dysentery he had from twelve to twenty-four stools daily and complained of pain in the abdomen and much straining at stool.

He was brought to the out-patient department of Touro Infirmary Sept. 4, 1913. A rectal tube was passed, amebas found, and he was given emetin, $2 / 3$ grain. The following day his mother reported that though the stools were liquid and there were four in the twenty-four hours she had

TABLE 3.-DATA IN CASE 4*

\begin{tabular}{|c|c|c|c|c|c|c|c|c|c|c|c|c|c|c|c|c|c|}
\hline \multirow[b]{2}{*}{$\begin{array}{l}\text { Date } \\
1914\end{array}$} & \multirow{2}{*}{$\begin{array}{c}\text { Temp. } \\
\text { Min. } \\
\text { and } \\
\text { Max. }\end{array}$} & \multirow[b]{2}{*}{ Med. } & \multirow[b]{2}{*}{$\begin{array}{l}\text { Tube } \\
\text { Passed }\end{array}$} & \multirow[b]{2}{*}{ Ameba } & & \multirow[b]{2}{*}{ Description } & \multirow[b]{2}{*}{ Remarks } & \multirow[b]{2}{*}{ Diet } & \multicolumn{7}{|c|}{ Blood } & \\
\hline & & & & & & $\frac{\text { ools }}{\mid \text { Night }}$ & & & & $\underset{\%}{\mathrm{Hb}}$ & R.B.C. & W.B.C. & $\begin{array}{c}\text { Neut. } \\
\%\end{array}$ & S.L. & $\underset{\%}{\mathrm{I} . \mathrm{M}}$ & Eos. & $\underset{\%}{\text { Bas. }}$ \\
\hline$\overline{5 / 26}$ & 100 & $\ldots \ldots \cdots$ & $\cdots$ & … & $\cdots \cdots$ & 1 & Large: brown; & Slept well............ & Liquid & & & & & & & & \\
\hline $5 / 27$ & $100 \quad-100.5$ & & + & + & 1 & 0 & Large; brown; & Slept well.......... & Liquíd & 30 & & 16,000 & 75 & 25 & & & \\
\hline $5 / 28$ & $99.5-100$ & $\begin{array}{l}\text { Emetin } \\
1 \mathrm{gr} .\end{array}$ & + & + & 2 & 0 & $\begin{array}{l}\text { Large; brown; } \\
\text { mueus; blood }\end{array}$ & Slept well........ & Soft & $\cdots$ & & & 65 & 30 & 3 & 1 & $\mathbf{1}$ \\
\hline $5 / 29$ & $99 \quad-100$ & $\begin{array}{l}\text { Expetin } \\
1 \mathrm{gr} .\end{array}$ & + & + & 1 & 0 & $\begin{array}{l}\text { se m is olid } \\
\text { brown; little } \\
\text { blood and mucus }\end{array}$ & Slept well... & Soft & .. & $2,500,000$ & 12,500 & & & & & \\
\hline $5 / 30$ & $09 \cdot 100$ & & + & - & 0 & 0 & & & & & & 11,400 & 75 & 21 & 2 & 1 & 1 \\
\hline $5 / 3 i$ & $99 \quad-100.4$ & $\begin{array}{c}\text { Castor oil } \\
1 / 2 \mathrm{oz} .\end{array}$ & + & - & 1 & 0 & Mueus; no blood & $\ldots$ & 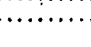 & $\cdots$ &. & 8,100 & 63 & 33 & 2 & 1 & 1 \\
\hline $6 / 1$ & $99-99.8$ & $\ldots \ldots \ldots \ldots$ & + & - & 0 & 0 & $\cdots \cdots$ & $\cdots$ & & 35 & & 9,200 & 66 & 23 & 9 & 2 & \\
\hline $\begin{array}{l}6 / 2 \\
6 / 3\end{array}$ & $\begin{array}{ll}99 & -100 \\
98 & -99.5\end{array}$ & Castor oil & $\begin{array}{l}+ \\
+\end{array}$ & 二 & $\begin{array}{l}0 \\
0\end{array}$ & $\begin{array}{l}: \\
0 \\
0\end{array}$ & 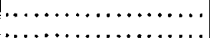 & .. & . & 30 & $\cdots$ & 12,083 & $\begin{array}{l}61 \\
58\end{array}$ & 33 & 5 & 1 & \\
\hline $6 / 4$ & $98 \cdot 99.5$ & $16 \mathrm{oz}$ & & & 0 & 0 & & & & 25 & & $10,2-0$ & 58 & 38 & 3 & 1 & \\
\hline $6 / 5$ & 98.3- 99.4 & $\begin{array}{c}\text { Mag. Sulph. } \\
\text { I dr. }\end{array}$ & $\ddot{+}$ & $\because$ & 0 & 0 & & $\cdots$ & .. & 30 & & $\begin{array}{l}12.239 \\
11,210\end{array}$ & $\begin{array}{l}57 \\
50\end{array}$ & $\begin{array}{l}38 \\
34\end{array}$ & $\stackrel{3}{15}$ & 2 & \\
\hline $\begin{array}{l}6 / 6 \\
6 / 7\end{array}$ & $\begin{array}{l}98.3-99 \\
99-100.4\end{array}$ & 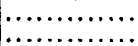 & + & - & $\begin{array}{l}0 \\
1\end{array}$ & $\begin{array}{l}1 \\
0\end{array}$ & Normal & & & & & & & & & & \\
\hline $\begin{array}{l}6 / 8 \\
6 / 9\end{array}$ & $\begin{array}{l}99-100 \\
98.3-99\end{array}$ & $\begin{array}{l}\text { I. Q. S. } \\
\text { I. Q. S. }\end{array}$ & + & $-\ldots$ & $\begin{array}{l}0 \\
0\end{array}$ & $\begin{array}{l}0 \\
2\end{array}$ & Inrmal & & & $8 \bar{i}$ & & 10,100 & 55 & 30 & 14 & 1 & \\
\hline $6 / 10$ & $09.2-100$ & Mag. Sulph. & $\cdots \cdots \cdots$ & (n..... & 0 & 3 & Normal........... & Coughed & & & & & & & & & \\
\hline $\begin{array}{l}6 / 11 \\
6 / 12\end{array}$ & $\begin{array}{l}99 \\
98.3\end{array}$ & Castor oil & $\begin{array}{c}+ \\
\cdots \cdots\end{array}$ & - & $\begin{array}{l}0 \\
0\end{array}$ & $\stackrel{0}{2}$ & normal...... & & Fuli & 30 & & 6,853 & 43 & 46 & 9 & 1 & 1 \\
\hline
\end{tabular}

* Urine negative except for indican.

as five stools daily and that the day before (August 23) he had vomited after drinking pop, had high fever and complained of pain in his stomach. While at home he had caten everything. He had had a cold for the past week. He was readmitted into Touro Infirmary. He had a cough but examination was otherwise negative. His bowels were constipated. Physical examination was negative. On passing the tube no amebas were found. His urine examination was negative except for a small amount of indican. His blood showed a total white count of 9,300 , small lymphocytes 35 per cent., large mononuclears 8 per cent., polymorphonuclear neutrophils 57 per cent.

The tube was passed again on August 26 with negative findings. There were no ova found at any time in his stools. Frequent reports have been received about the patient's condition and up to the present time, eleven months afterward, he has remained cured.

CASE 3.-A. M., white male, 4 years old, native of Louisiana and resident of New Orleans, came to my clinic at Touro Infirmary on Sept. 2, 1913, because of frequent and bloody stools.

His father and mother and brother were all living and healthy. There was no dysentery in the family.

The patient was a full term child of normal delivery. He was breast fed exclusively for twelve montins after which table food was acded to his diet and at 21 months the breast noticed no bloorl, but some mucus. The passing of the tube showed amehas and he was given 1 grain emetin.

Sept. 6, 1913, there was a tendency toward constipation. The tube again showed amebas and he was given emetin, 1 grain. After this the mother did not return for the treatment and the patient was recorded as having deserted. Five days later she returned and the examination after passing the tube was negative. She brought the patient back on two occasions convenient for herself, and then again discontinued reporting.

Oct. 2, 1913, the patient was brought back to the clinic complaining that on September 27 blood reappeared in his stools and had continued daily since then. The stools were yellowish, the blood being passed mostly at the end of the stool. October 2, however, the stool was blackish. The patient had a good appetite and had eaten everything he wanted. On passing the tube amebas were found and the patient was given emetin, 1 grain. The next day the patient did not return. On the third day amebas were found again and emetin, 1 grain, was given. The mother then took it on herself not to return with the patient for further treatment as the clifld had improved, and the patient was again recorded as having deserted.

November 4 the patient was brought to the Touro outpatient department for the treatment of the same condition (frequent, bloody stools). The mother hesitated a long tirne 
before returning because she had discontinued of her own accord on the rievious occasions. As there were no empty beds at Touro Infirmary and as it was believed best to treat the child in hospital, he was admitted into my service at Charity Hospital.

On admission he was given a dose of castor-oil. The next day the tube showed amebas in great numbers. He was given emetin, 1 grain daily, as long as amebas were found and for two days longer because of his previous unsatisfactory treatment. After the first twenty-four hours no active amebas were found and likewise after the second twenty-four hours. No amebas wire seen for two consecutive days thereafter. The tube was then passed every other day for four days and finally twice weekly so that observations were carried over a period of three weeks. During his stay in the hospital it was extremely difficult to keep the patient in bed and whenever lie saw the opportunity he would get up and play about in the ward.

His stools became a little loose and contained a small amount of mucus, but his mother took him away without his being discharged.

He returned again on Feb. 11, 1914, for the same condition. The treatment was again instituted and after four doses of emetin, 1 grain daily, it was discontinued as amebas were no longer found. After the first dose his bowels did not move but when they did move after the third dose there was no blood. Un passing the tube three days after the last dose of emetin the presence of a few red blood-corpuscles caused the treatment to be begun again. Though no amebas were found he was given 5 grains of emetin in six days, one day being omitted through error. The tube was passed regularly after this and no further positive or suspiciols findings were made. His mother took the patient away, afier he had contracted a slight bronchitis on March 2, 1914, before he was discharged.

Since the last attack, which was treated under more favorable conditions than the previous ones, the patient remained well un to a report of one week before this was written.

CASE 4.-M. R., white male, $85 / 12$ years old, native of Louisiana and resident of Donaldsonville, La., was brought to my clinic at Touro Infirmary, May 26, 1914, for frequent stools containing blood.

$\mathrm{He}$ is the fifth child of eight, all of whom are healthy, as are the parents. His mother had four miscarriages and one stillbirth. An aunt died of tuberculosis five years ago. He was a full-term child of normal delivery and was breast fed for three months, after which he was given the bottle with milk and sweetened water.

Aside from the present illness he had never been sick. $\mathrm{He}$ usually drank cistern water and never well water. Three years ago a short time after eating of peanuts he passed much gas and later blood appeared in his stools. There were intervals when the dysentery would be much better, but recently ne liad become much worse. During the attacks he had much pain in his abdomen and strained a great deal at stool. The jain was more severe during the first three months of the iliness. He had never had much fever. Four physicians wete consulted at various times but none had ever made the diagnosis. One advised bringing him to the hospital. His mother thought that he was gradually becoming worse. He had never been confined to bed before he was admitted on May 26, 1914.

His stools were large, brown and contained mucus and blood. The 1ube was passed, amebas found and emstin, 1 grain, given. In all he was given 2 grains of emetin by needle after which the amebas were no longer found and the blood stopped. The tube was passed every day for four days after the first negative finding, then two days later with the same result. He was given castor-oil twice and magnesium sulphate twice and no amebas were found on passing the tulie following the administration of the purgatives. Not much time has elapsed since this case was first treated but the patient is improving nicely.

\section{DISCUSSION}

Case 1 came from a district low and swampy and is of interest from a diagnostic point of view and because of the age of the patient.

Case 2 was given $32 / 3$ grains emetin in four days. There was no blood after the second dose of emetin and no amebas were found after the fourth dose of emetin. This case is of especial interest because of the small amount of nredication used; the prompt effect of the emetin in a case of such long duration ( 8 months); and the results of the treatment, eleven months having elapsed with no return of the illness.

Case 3 cannot be considered a fair test of any treatment, because (1) the first two attacks were treated without rest owing to the refusal of the parents to permit the patient to be admitted into the hospital; (2) the first two treatments were not completed; (3) during the third attack the patient was not kept in bed, and just at the time he should have been more closely observed, he deserted; (4) the fourth attack may have been due to no rest; and because (5) of the lack of intelligence and cooperation on the part of the parents, who gave the child all sorts of food when visiting him.

It must be borne in mind that there is a possibility of reinfection in this case, especially when the hygiene and habits (which were unfavorable) of the patient are considered.

The vomiting must be mentioned, as it is possible, though hardly probable, that the emetin alone caused it, because he did not vomit after each dose.

This case is of particular interest because of the relapses which may be accounted for as already mentioned. Also because it demonstrates the promptness of the effect of emetin in controlling the symptoms and the harmlessness of its large and continued dosage, and of its ultimate effect in the treatment.

It is too early yet to venture much in Case 4; suffice it to say, however, that the prompt effect of emetin was again demonstrated, since after the administration of 2 grains of emetin given in two days the blood disappeared and no amebas were found in the stools, and the effect was so prompt in a case of such long standing, ( 3 years).

All three patients were given 1 grain doses of emetin hypodermatically, and though it might be considered a large dose, no harmful effects restulted even in Case 3 , in which the patient was given the drug on so many occasions and during one attack 5 grains in six days.

From the study of the foregoing cases and the literature $I$ believe that emetin is the specific for amebic dysentery. There are some observers who have recorded cases treated satisfactorily and which have remained cured. There are others who have not reported such satisfactory results.

In the foregoing cases the effect of emetin was spectacular. After its administration the blood in the stools disappeared as if by magic; the amebas were soon no longer found, the stools were promptly diminished in frequency, and there was a tendency toward checking the bowels altogether and giving the necessary rest. Is there anything more to be desired? Undoubtedly it is the drug for children with amebic dysentery, as it may be given to them while quite young, its effect is rapid, and there are no disadvantages experienced as in endeavoring to have the child swallow ipecac pills or the inconvenience and struggle incident to colonic irrigation, and its effect is certain.

Maison Blanche Building. 


\section{ABSTRACT OF DISCUSSION}

Dr. Thomas S. Southworth, New York: We of the North are prone to look on amebic dyseritery as a matter of warm climates and the tropics. We see few cases, even in adults, unless the persons have been in some other portion of the country. Yet I doubt whether cases of dysentery have been sufficiently investigated for the presence of the ameba. Last summer I had an opportunity of seeing a woman of nearly 80 who had traveled only between Ohio and Maine, yet she had amebic dysentery which was promptly checked by the use of emetin hypodermatically. In these days when so much of our garden produce and fruit comes to ts from the southern states, it is perfectly possible that the origin of this infection can be brought to us, and we should be more on the outlook for these cases in children. I believe we shall find more of them if we are watchful.

Dr. Henry Dwight Chapin, New York: This disease does occur rarely in New York. Every year we have one or two cases in the babies' ward of the Post Graduate Hospital. These patients have $n^{r t}$ been out of New York. Perhaps the disease is more common than we think, and we have not looked with sufficient diligence for the ameba.

Dr. J. W. Amesse, Denver: Any contribution to our knowledge of amebic dysentery should be welcomed, not only by this Section, but by the entire Association. It was a matter of common observation and comment among those who served in the Philippines during the early days of our occupation, that while amebic dysentery in adults was the bete noire of our daily life, few if any cases were found in children. I belicve there is a relative age immunity to this disease, as there is to yellow fever, just as we find a relative race immunity among certain peoples to typhoid, hookworm disease, etc. So far as emetin is concerned, reports from every quarter warrant us in asserting that this powerful remedy is a specific for amebiasis comparable with quinin in malaria and antitoxin in diphtheria. I have seen amazing results follow its use in the practice of a colleague. Soldiers and civilians invalided home years ago and suffering periodic recrudescences of dysentery, have become practically transformed, and have again taken up their work as productive nembers of society.

Dr. W. W. Butrerworth, New Orleans: The amebas in this country are wide-spread and not confined to the South. Neither are all amebas pathogenic. It is only when we have recurring attacks of dysentery, bloody mucus and straining, which pass away in a few days if not treated, to recur again, that our attention is called to the pathogenic amebic dysentery. Therein lies the important diagnostic point between pathogenic amebic dysentery and ordinary dysentery. I had an interesting experience in New Orleans, with a soldier who returned from the Philippines. He had barely escaped death in those islands; he was a married man, with a family of four children, the youngest of whom was 13 months old. This child was partially breast-fed. It was found to have amebic dysentery. Two of his other children, his wife and himself suffered from the same disease. It seems fairly reasonable that the infection occurred through the person of this returned soldier. I heartily concur in the value of emetin. It is the best agent we have in the treatment of this disease. Treatment by ipecac and flushing is most distressing and most annoying, and is frequently foregone by the patient. They will not subject themselves or their ciniid to sucin a treatment. Emetin is far and away the best treatment we have of this condition.

Farmers Being Paid for Milk on Score-Card Basis.-For the past year or two the larger milk companies selling milk in this city have purchased milk from dairy farmers on the score-card basis. In general the contract provides for a premium of 10 cents per hundredweight for a score above 68 , particular attention being given to methods of operation. That this is an effective incentive to the dairy farmer to produce milk according to modern standards is not open to question.-Weckly Bull. Dept Health, City of New York.

\section{A YEAR'S EXPERIENCE WITH CON- TAGIOUS-DISEASE NURSES*}

\author{
WM. H. PRICE, M.D. \\ DETROIT
}

This paper assumes as established the fact that the taking of wholesome ways and reasonable precautions for the benefit of the public health may be expected to result in the prevention of disease, a healthier community, and more efficient individuals with lengthened lives. The truth of such a statement has come to be a matter of common knowledge. If evidence of it were needed, however, it is available in abundance, as witnessed by those spectacular sanitary reforms with which the world, lay as well as professional, is familiar.

With the prospect of such a reward, of disease prevented, dependents and public charges eliminated, and individual and community resources conserved, it is a source of wonderment that the preventable waste of disease and physical deficiencies continues to be endured. The explanation can only be in a lack of appreciation of these facts by laymen, by many physicians, and especially by those having in charge the appropriation of the public funds, when the principle of disease prevention is applied to their own household or community. It has therefore followed in natural sequence that education of the public has come to be a fundamental recourse for all activities having for their aim the protection and promotion of the public health. Some authorities even go so far as to state that efficient health measures are 80 per cent. educational.

Control of contagious disease is a rudimentary principle to be observed by all authorized public-health agencies. There are two reasons for this:

First, the problems of the control of communicable diseases are reduced to scientific exactness, and therefore greater results may be expected from the time, money and effort expended.

Secondly, public education regarding the possibility and advisability of reducing these diseases has progressed to such a point that the public demands their suppression as a prerequisite to the granting of further support, both moral and financial, for measures directed at more obscure diseases and defects in which all progressive health departments are interested, namely, housing, occupational, industrial and hereditary.

When, therefore, we embark on any program for the protection of the public health, it follows as a natural corollary that the suppression of contagious diseases is a prime requisite, and that the method of personal education directed at the known foci of infection is of greatest importance.

Previous to July 1, 1913, the following custom prevailed in Detroit relative to contagious diseases: The house was placarded immediately after the disease was reported. The next day a quarantine inspector visited the premises; his mission was to furnish fuel and groceries in needful cases, and to warn isolated persons against breaking quarantine. He called again as time and necessity indicated, and at the termination of the illness disinfected the house and removed the placard. Three inspectors were so employed at a salary of $\$ 1,000$ per year each. They were faithful,

* Read before the Section on Preventive Medicine and Public Healt at the Sixty-Fifth Annual Session of the Amerisin Medical Association,
Atlantic City, N. J., June, 1914. 